\title{
Hydrodynamic Modeling of Laguna Lake Using Environmental Fluid Dynamics Code
}

\author{
Armi M. Cunanan and Jonathan W.L. Salvacion
}

\begin{abstract}
In the Philippines, Laguna Lake is the biggest and one of the most important lakes. It is also the third largest inland body of water in Southeast Asia (Bongco \& Dalisay, 2012). It is being used for several purposes such fisheries, transport route, flood water reservoir, power generation, recreation, irrigation, industrial cooling, waste sink, and source of potable water since July, 2009 (LLDA, 2014). Majority of the lake water is classified by the Water Quality Criterion as Class C (LLDA, 2008). The watershed is composed of igneous and sedimentary rocks, which have been mainly characterized by sedimentary rocks overlain by alluvial deposits (Philippine Sub-Global Team, 2005). As one with the utmost significant water body in the Philippines, it dictates a need for a hydrodynamic model using the updated available bathymetry data. This study intends to create a hydrodynamic model of Laguna Lake using Environmental Fluid Dynamics Code (EFDC) wherein the data used in the initial condition of this study is the most recent available bathymetry data of the lake as of January, 2014 from the Laguna Lake Development Authority (LLDA). Curvilinear grid was used to generate the 9889 active cells in the EFDC model. The boundary conditions significant to this study are the wind, atmospheric and temperature data series, all of which are gathered from the Philippine Atmospheric, Geophysical and Astronomical Services Administration (PAGASA). Wind data series includes time, speed and direction of the wind; atmospheric data series includes time, atmospheric pressure, dry temperature, fraction of relative humidity, amount of precipitation, open evaporation condensation, solar radiation and amount of cloud present in the sky. In order to calibrate the hydrodynamic model created, the researcher conducted field surveys in strategically selected locations to get the velocity on the surface, middle and bottom layer of the lake representing the west, central, east and south bays of Laguna Lake.
\end{abstract}

Keywords—EFDC, Hydrodynamics, Laguna Lake, Velocity

Manuscript received December 10, 2015. This work was supported by Mapua Institute of Technology and Department of Science and Technology - Engineering Research and Development for Technology

A.M. Cunanan is currently a Phd student in Mapua Institute of Technology, Intramuros, Manila, Philippines (e-mail: armicunanan@yahoo.com).

J.W.L. Salvacion is currently the Dean of School of Graduate Studies of Mapua Institute of Technology, Intramuros, Manila, Philippines (e-mail: jlsalvacion@mapua.edu.ph).

\section{INTRODUCTION}

Laguna Lake is located at $14.3833^{\circ} \mathrm{N}, 121.2500^{\circ} \mathrm{E}$, Southeast of Manila between the provinces of Laguna to the South and Rizal to the North (Mitsumoto \& Santiago, 2001). It has three distinct bays namely West Bay, Central Bay and East Bay. The southernmost portion is called the South Bay. The Laguna Lake or Laguna de Bay is a large shallow freshwater body with an average depth of 2.5 meters, a surface area of 911 $\mathrm{km}^{2}$, a shoreline of $220 \mathrm{~km}$ and a holding capacity estimated at $2.19 \times 10^{9} \mathrm{~m}^{3}$ (Bongco \& Dalisay, 2012). It traverses 12 cities, 49 municipalities, and 2,656 barangays or villages (Philippine Sub-Global Team, 2005).

Millennium Ecosystem Assessment conducts assessments at sub-global scales because ecosystems are highly differentiated in space and time, and because sound management requires careful local planning and action. The sub-global assessments will directly meet the needs of decision-makers at the scale at which they are undertaken, strengthen the global findings with on-the-ground reality, and strengthen the local findings with global perspectives, data, and models (Philippine Sub-Global Team, 2005). According to the Philippine Sub-Global Assessment by Millennium Ecosystem Assessment, general conditions of Laguna Lake are poor and deteriorating, although fish production is still in good condition, shore land rice production is in good state, and biodiversity of the forest ecosystems with in the lake's area is still in good condition although declining. The pressures in Laguna Lake such as higher water demand, wastewater disposal, and fishing activity increase, are being caused by nearby provinces' increasing population and rapid developments. These brought about the need to have a comprehensive and integrative approach to model water quality and quantity and necessitate the need for a hydrodynamic model (Tamura et al., 2003). The movement of water in any water body is very important because it is the result of all the forces acting on or the external forces and the internal forces acting or the properties of the water itself which are all being dealt under hydrodynamics. Since it is very difficult to monitor and study the behaviour of water bodies, hydrodynamic models are done to be able to mimic the activities of a water body by inputting its internal and external driving forces (Ji, 2008).

Environmental Fluid Dynamics Code (EFDC) model is a comprehensive three dimensional dynamic tool, widely recognized simulation platform and a multi-task, highly integrated modular computational environmental fluid dynamics package (Wang et al., 2013; Zhao et al., 2013). It can be used for understanding and predicting the environmental 
fluid flows with transportation and mixing associated dissolved or suspended materials, and is technically defensible 3D hydro-environmental modeling tool for pollutants and pathogenic organism transport and fate from point and non-point sources (Wang et al., 2013).

The EFDC comprises an advanced three-dimensional surface water modeling system for hydrodynamic and reactive transport simulations of rivers, lakes, reservoirs, wetland systems, estuaries, and the coastal ocean (J. M. Hamrick, 1992a). The modeling system was originally developed at the Virginia Institute of Marine Science as part of a long-term research program to develop operational models for resource management applications in Virginia's estuarine and coastal waters (J. M. Hamrick, 1992b). The EFDC model is a public domain, has been used for more than 80 modeling studies of rivers, lakes, estuaries, coastal regions and wetlands in the United States and abroad, with current users including universities, governmental agencies, and engineering consultants. Tetra Tech, Inc., currently maintains EFDC and continues its development with primary support from the US Environmental Protection Agency. (John M. Hamrick \& Mills, 2000) (J. Hamrick, 2002).

\section{ENVIRonmental Fluid Dynamics Code Simulation}

\section{A. EFDC Coordinate System}

The EFDC model solves the three-dimensional, vertically hydrostatic, free surface, turbulent averaged equations of fluid with variable density. The model uses a stretched or sigma vertical coordinate and Cartesian or curvilinear, orthogonal horizontal coordinates. The hydrodynamic model also solves dynamically coupled transport equations for turbulent kinetic energy, turbulent length scale, salinity, and temperature (Meghna Babbar-Sebens, 2013).

The vertically hydrostatic momentum and continuity equations of EFDC model for turbulent flow are solved in a coordinate system which may be curvilinear and orthogonal in the horizontal and stretched or topography-free surface in vertical direction. (Wang et al.) (John M. Hamrick \& Mills, 2000)

EFDC uses stretch or sigma vertical coordinates and cartesian or curvilinear, orthogonal horizontal coordinates to represent the physical characteristic of a water body. (Wu \& $\mathrm{Xu}, 2011)$

\section{B. Simulation Process}

The use of EFDC involves three most important stages to be carried out as shown in Figure 1. Details of pre-processing stage is shown in Figure 2 which is basically the assembling of all necessary inputs to come up with a hydrodynamic model which will be simulated based on the chosen module. The processing stage involves the simulation of the software. The post-processing involves viewing the model results as necessary based on the available viewing options to show the results of the simulation.

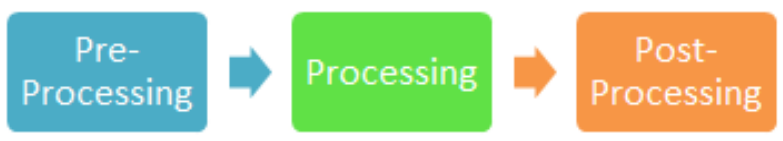

Figure 1 EFDC Simulation Scheme

The pre-processing stage starts with the input of the latitude and longitude of the Laguna Lake study area. A third party website, geoplanner.com, was utilized to acquire the coordinates. The bathymetry and depth of Laguna Lake was acquired from Laguna Lake Development Authority (LLDA) together with the stream flow and its water balance which are vital input for the boundary conditions since the resulting flow and direction of the lake basically depends on it. Active module selection enables the user to choose the desired module to be utilized. Model run timing contains the options for the total number of simulations, and time the time step to be used. The hydrodynamics contains option for input of wind data series and computes the coriolis factor. The temperature provides option to input the temperature time series. After completing all these, the hydrodynamic model is ready for simulation.

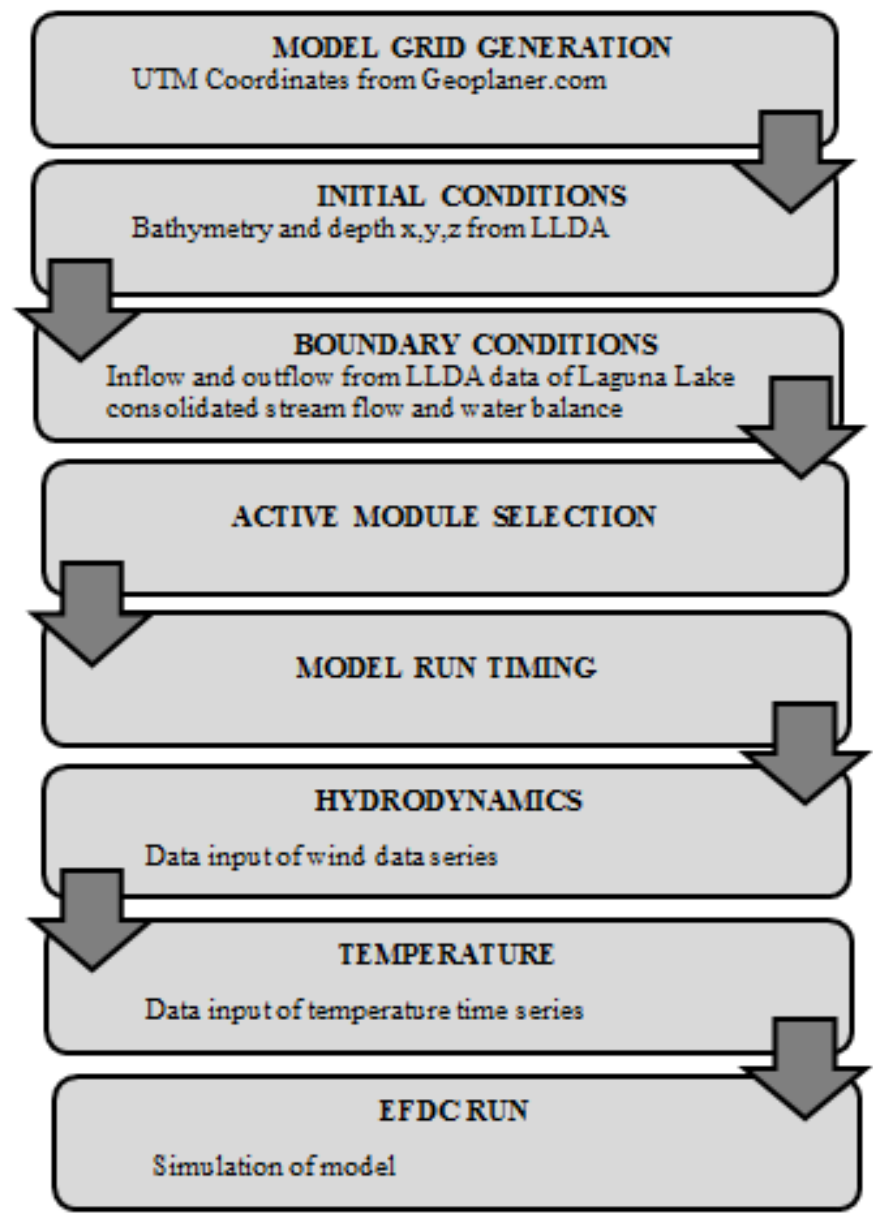

Figure 2 EFDC Pre-Processing

\section{Velocity Field Survey}

To be able to calibrate the values obtained from the EFDC model simulation of the velocities of Laguna Lake, field surveys were conducted. The field survey included actual 
acquisition of the flow, so as velocity may be computed and wind speed measurement in Laguna Lake using General Oceanics Environmental Mechanical Flowmeter (G.O. Environmental). Table 1 contains the latitude and longitude in west bay, central bay, east bay and south bay where the survey of velocities took place.

TABLE 1 LOCATIONS OF FIELD SURVEY POINTS (LATITUDE AND LONGITUDE)

\begin{tabular}{|c|l|l|l|}
\hline $\begin{array}{c}\text { FIELD SURVEY } \\
\text { POINT NUMBER }\end{array}$ & LOCATION & LATITUDE & LONGITUDE \\
\hline 1 & Paete, Laguna & 14.3586 & 121.4624 \\
\hline 2 & Pililla, Rizal & 14.4759 & 121.2988 \\
\hline 3 & Binangonan & 14.4616 & 121.1906 \\
\hline 4 & Angono & 14.5150 & 121.1400 \\
\hline 5 & Biñan, Laguna & 14.3600 & 121.0898 \\
\hline
\end{tabular}

The following procedures and peripherals were carried out and used during the duration of the field survey.

\section{G.O. Environmental Flowmeter}

The flowmeter is a general purpose instrument for flow measurements. The flowmeter has a precision molded rotor coupled directly to a six digit counter that registers each revolution of the rotor on a counter within the body of the instrument (Oceanics, 1980)

For each survey point, three depths were monitored, surface (just enough to submerge the flowmeter in water), $1 \mathrm{~m}$ and $2 \mathrm{~m}$ deep from the surface. The rotor of the flowmeter was positioned in accordance with the four cardinal directions, North, South, West and East. Readings were taken at 120 seconds interval. The actual readings from the flowmeter were recorded and manipulated to produce the water velocity.

To ensure that the GPS device is showing the correct coordinates, each of the coordinates were compared to the latitude and longitude from a mobile device's GPS function.

\section{Flow Meter Reading}

The number of revolutions the flowmeter that is registering on the G.O. Environmental flowmeter device is in counts per second (cts/sec).

For slow velocity such as in this study it is advisable to utilize equation (1) and (2).

$$
\text { Distance }(\mathrm{m})=\frac{\text { difference in counts } \mathrm{x} \text { rotor constant }}{999,999}
$$

Equation (1) was used to determine the distance in meter the water travelled. The difference in counts is the flow meter reading before and after it was submerged into the lake. According to the G.O. Environmental, the standard rotor constant for the flowmeter used in this study is equivalent to 26.873 (unit less). The value of the distance computed from equation (1) was used in equation (2) to be able to arrive with the value of speed. The divisor used is the actual duration of time the flowmeter was submerged.

$$
\text { Speed }\left(\frac{\mathrm{cm}}{\mathrm{s}}\right)=\frac{\text { distance }(\mathrm{m}) \times 100}{\text { time in seconds }}
$$

\section{EFDC Simulation AND ACtuAl Field SuRvey Results}

\section{A. EFDC Model Water Velocity}

The simulated hydrodynamic model generated the graphical illustration of the velocity and flow of Laguna Lake. The researcher chose 4 periods (months) to represent the one year simulation of the 2 seasons of the Philippines, the wet and dry season. The months of March (Day 90) and May (Day 150) represent the summer monsoon and the months of October (Day 300) and December (Day 365) represent the winter monsoon. As shown in Figure 3, the velocity in $\mathrm{m} / \mathrm{s}$ are written in Arabic numbers and the arrows denotes the direction of the flow of water in the three main bays of Laguna Lake names, West Bay - located on the western part of the lake, Central Bay - located at the middle part of the lae and the East Bay - located on the eastern side of the lake.

The average wind velocity considered for the month of March is at a rate of $2.2358 \mathrm{~m} / \mathrm{s}$, which is similar to the velocity for the month of February. Only, for the month of March, the wind is blowing to the direction of southeast. The waters in the west bay also flows upward, whereas, majority of the locations shown in the central bay, its waters flows downward, then breaks at the south part of the bay, wherein some flows towards the west bay and some flows towards the east bay. Behavior of the water in the east bay is almost the same with the previous months, January and February.

For the month of May, wind considered is $2.6829 \mathrm{~m} / \mathrm{s}$ towards southeast, which is the same of the month of April. The water in the upper part of the west bay flows upwards, but the water on the lower part of Laguna Lake's east bay is starting to flow clockwise towards the east bay.

From the southwest wind direction of the previous months, the wind now is blowing at the direction northeast at a rate of $1.7886 \mathrm{~m} / \mathrm{s}$ on the month of October. This wind pattern is similar to the November, December and January wind pattern. The uppermost of the west bay is flowing upwards towards the Pasig River, and the rest of the water in the central and east bay is flowing counter clockwise.

The wind velocity at the month of December is $1.7886 \mathrm{~m} / \mathrm{s}$ with a direction of southeast, similar for the months of October, November and January. More of the west bay water is flowing upwards as compared from the November's water flow pattern. Central bay and east bay flows downward and counter clockwise, respectively.

Figure 3 shows the values of water velocity on several points of the lake together with its corresponding direction of flow for the months of March, May, October and December. 

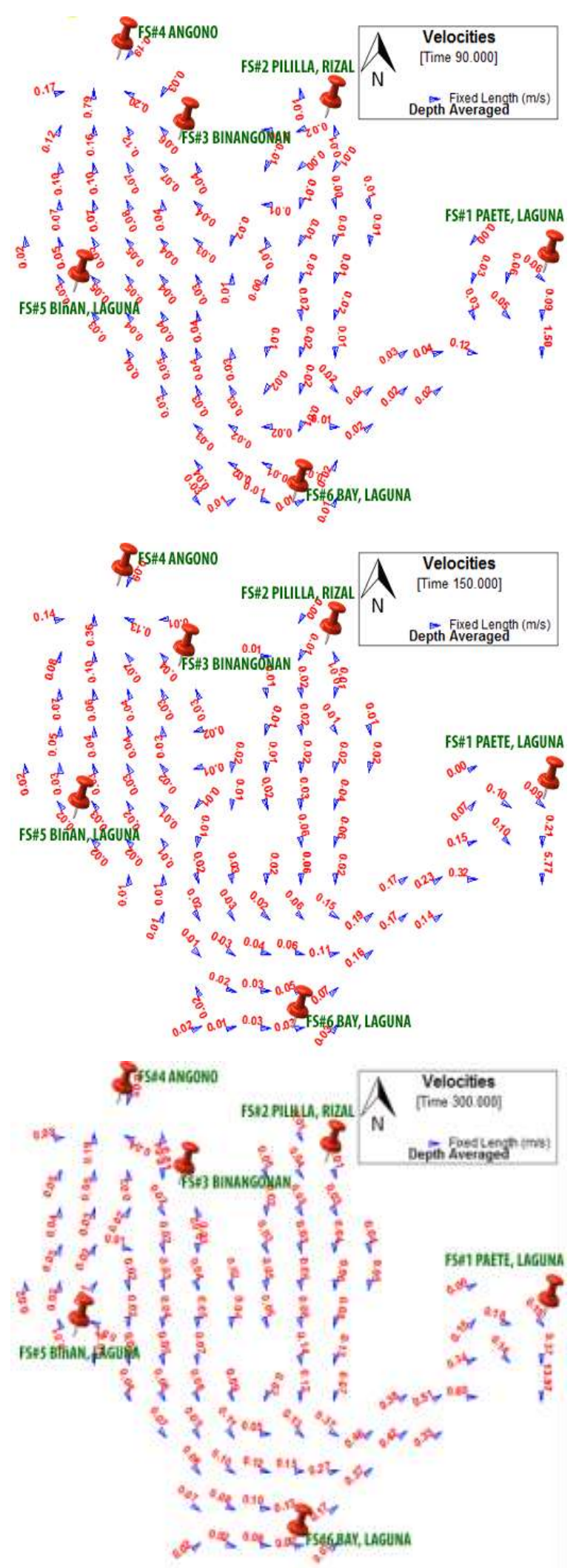

http://dx.doi.org/10.15242/IJRCMCE.AE01162009

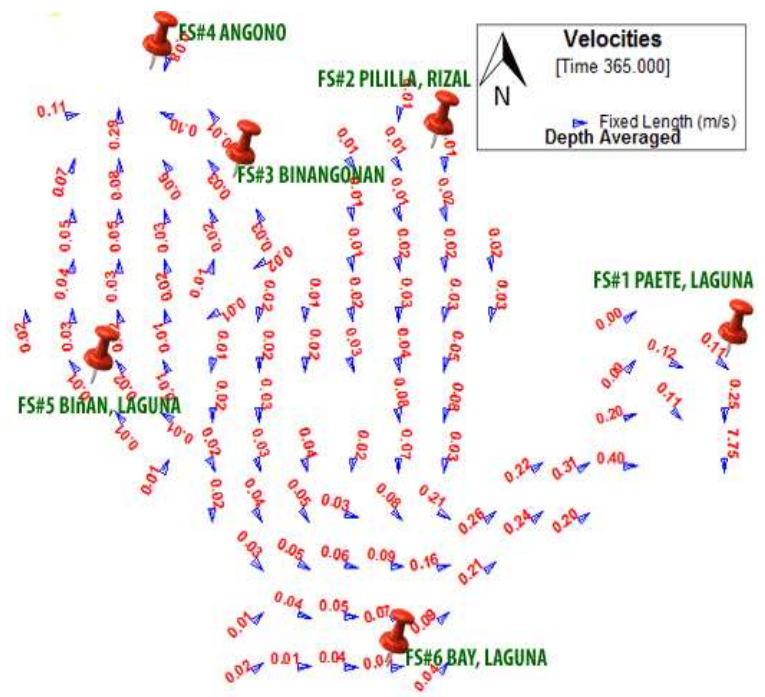

Figure 3 EFDC Model Output of Water Velocity for the Months of March, May, October and December

\section{B. Summary of Water Velocity from EFDC Results}

The results of the simulated hydrodynamic models velocity were plotted against the Laguna Lake map and on the locations where the field surveys were conducted. The calibration of the water velocity took place on the month of March, thus the results were potted on day 90 (month of March) screenshot results. The summary of the computed average velocity from EFDC are plotted on Figure 4.

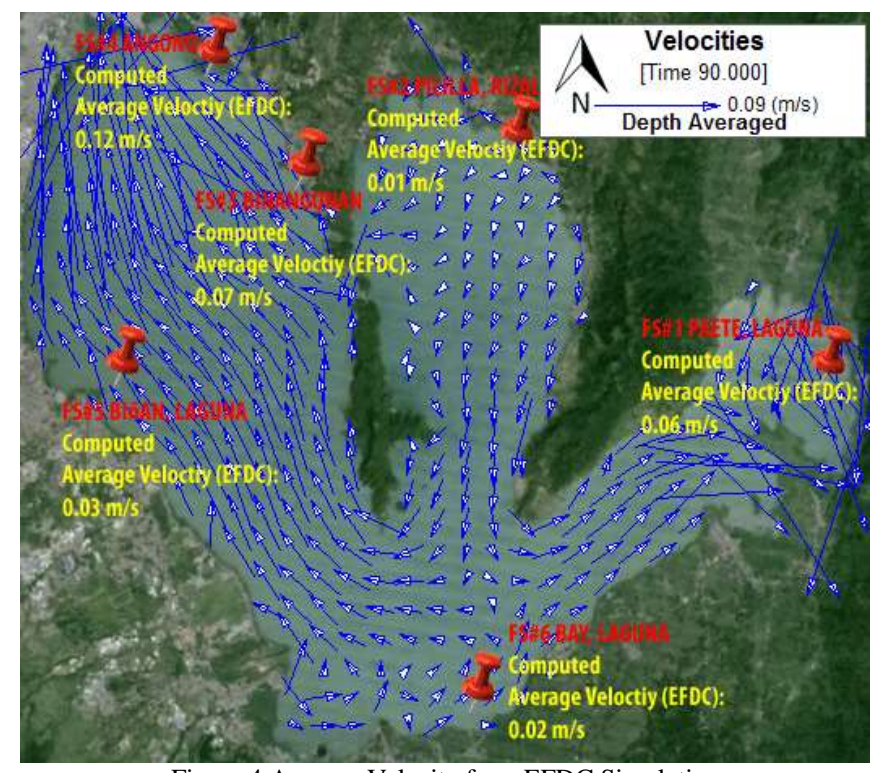

Figure 4 Average Velocity from EFDC Simulation

\section{Actual Field Survey Water Velocity Results}

The greatest value of velocity indicates the current direction of water during the field survey. Comparing the three depths considered in Field Survey \#1 Paete, Laguna, the velocity of water at the $2 \mathrm{~m}$ depth shows the greatest values at $0.0717 \mathrm{~m} / \mathrm{s}$ South and $0.0694 \mathrm{~m} / \mathrm{s}$ East. Though the water at the surface at $0.0627 \mathrm{~m} / \mathrm{s}$ South and $0.0605 \mathrm{~m} / \mathrm{s}$ East, is also dynamic due to the wind forcing acting upon the water and is comparable to the velocity at the 2 meters depth. Water is most 
calm at the middle or 1meter depth at $0.0470 \mathrm{~m} / \mathrm{s}$ South and $0.0537 \mathrm{~m} / \mathrm{s}$ East.

The highest value of velocity in Field Survey \#2, Pililla Rizal was recorded from the 2 meters depth of submerging the flowmeter at $.0179 \mathrm{~m} / \mathrm{s}$ South and $0.0202 \mathrm{~m} / \mathrm{s}$ East. The water at the surface at $0.0157 \mathrm{~m} / \mathrm{s}$ South and $0.0134 \mathrm{~m} / \mathrm{s}$ East and the water where it is most calm at the middle or 1meter depth at $0.0067 \mathrm{~m} / \mathrm{s}$ South and $0.0012 \mathrm{~m} / \mathrm{s}$ East.

The direction of water flow in Field Survey \#3 Binangonan, Rizal is towards North and West. From the field survey conducted, a velocity of $0.0717 \mathrm{~m} / \mathrm{s}$ towards North and 0.0649 $\mathrm{m} / \mathrm{s}$ towards West were the computed velocity for the surface. At the 1 meter depth, a velocity of $0.0672 \mathrm{~m} / \mathrm{s}$ towards North and $0.0582 \mathrm{~m} / \mathrm{s}$ towards west and at the 2 meter depth considered a velocity of $0.0739 \mathrm{~m} / \mathrm{s}$ towards North and .0358 $\mathrm{m} / \mathrm{s}$ towards West were computed.

Considering Field Survey \#4, Angono, Rizal, although the wind is blowing towards southeast, the direction of the flow of water is towards northwest. This is due to the fact that although the wind forcing is one factor for the direction of the flow of water, a greater forcing that affects the direction of the flow of water of the lake is the water balance. Going back to the data gathered from the LLDA, it was stated that the major discharge point of the lake is the Mania Bay, thru the Napindan Channel, or the Manggahan Floodway located near the field survey number 4 location. The direction of the flow of water is towards North and West, similar with Binangonan. $0.1411 \mathrm{~m} / \mathrm{s}$ towards North and $0.1097 \mathrm{~m} / \mathrm{s}$ toward West were the computed value of the velocity of water in the surface. For the 1 meter depth, $0.1321 \mathrm{~m} / \mathrm{s}$ towards North and $0.1276 \mathrm{~m} / \mathrm{s}$ towards west was computed. During the field survey, the water in Angono is less than 2 meters, thus no data was recorded for the 2 meter depth velocity calibration.

Dominating the direction of flow of water in the Field Survey \# 5 in Biñan, Laguna is North and West. $0.0291 \mathrm{~m} / \mathrm{s}$ towards north and $0.0336 \mathrm{~m} / \mathrm{s}$ toward west were the computed value of the velocity for the surface water. On the 1 meter depth considered, $0.0381 \mathrm{~m} / \mathrm{s}$ towards north and $0.0358 \mathrm{~m} / \mathrm{s}$ towards west were computed. Considering the fact and recorded data that the wind is blowing towards southeast for the month of March, the direction of water for Biñan is towards northwest since the water discharges at Pasig River at a rate of $150 \mathrm{~m} 3 / \mathrm{s}$. The wind forcing does not dictate the flow of water, instead the major contributor to determine its direction is the discharge points which are part of the boundary conditions established for the hydrodynamic model done.

Field Survey \#6 in Bay, Laguna also has a water depth of less than 2 meters. $0.0157 \mathrm{~m} / \mathrm{s}$ towards South and $0.0246 \mathrm{~m} / \mathrm{s}$ towards East were the computed velocity from the actual field survey at surface, and $0.0269 \mathrm{~m} / \mathrm{s}$ South and $0.0291 \mathrm{~m} / \mathrm{s}$ East were from a depth of less than 1 meter. On the location of Bay at the South bay, the direction of the water is torn between flowing West and East.

\section{Summary of Field Survey Results}

Figure 5 shows the summary of the values of velocities acquired from the field surveys conducted and is plotted on its respective locations. The Laguna Lake hydrodynamic model screenshot at 90 days or for the month of March was used to match the date of field survey conductance. The arrows denote the direction of the flow of water as a result of the simulation using EFDC.

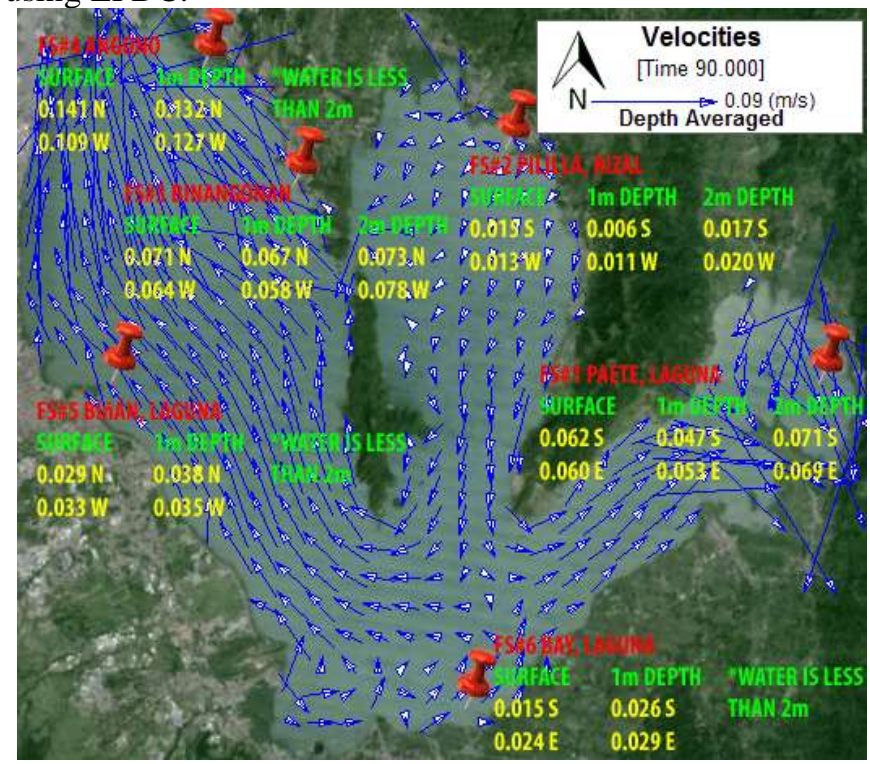

Figure 5 Plotted Summary of Field Survey Results

\section{E. EFDC Water Velocity vs Actual Field Survey Water Velocity}

Figure 6 summarizes the calibration results of the hydrodynamic model simulated in EFDC and the field survey conducted in the six (6) strategically chosen points. The computed average velocity in EFDC from Field Survey \# 1 located in Paete, Laguna is $0.06 \mathrm{~m} / \mathrm{s}$ and the field survey result is $0.061 \mathrm{~m} / \mathrm{s}$. For the Field Survey \# 2 located in Pililla, Rizal, the computed average velocity from EFDC is $0.01 \mathrm{~m} / \mathrm{s}$ and the prevailing field survey result is $0.008 \mathrm{~m} / \mathrm{s}$. In the Field Survey \#3, in Binangonan, Rizal, the computed average velocity from EFDC is $0.07 \mathrm{~m} / \mathrm{s}$ and the prevailing field survey result is 0.069 $\mathrm{m} / \mathrm{s}$. The computed average velocity result from EFDC in Angono, Rizal, the field survey location number 4 is $0.12 \mathrm{~m} / \mathrm{s}$ while the prevailing actual field survey result is $0.085 \mathrm{~m} / \mathrm{s}$. In Biñan, Laguna, Field Survey\# 5 has its computed average velocity at $0.03 \mathrm{~m} / \mathrm{s}$ whereas the field survey conducted is $0.023 \mathrm{~m} / \mathrm{s}$. Field Survey \#6 located in Bay, Laguna resulted to a value of $0.02 \mathrm{~m} / \mathrm{s}$ and the result of the field survey conducted is $0.024 \mathrm{~m} / \mathrm{s}$. For each of the above mentioned results, both the computed average velocity from EFDC and the actual field survey conducted closely agrees with each other. 


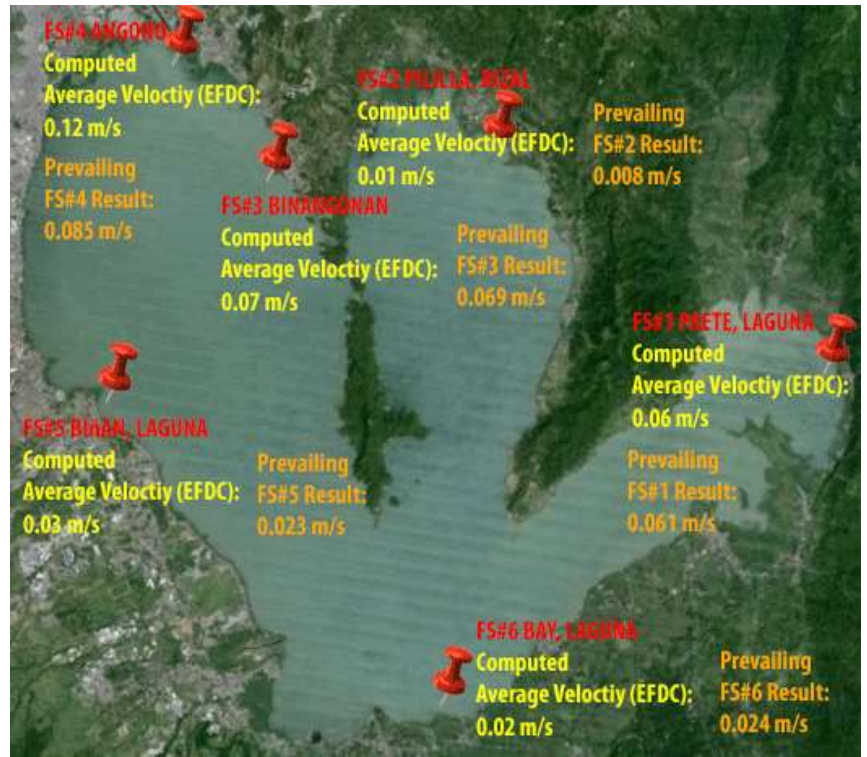

Figure 6 EFDC Velocity Results vs Prevailing Field Survey Result

\section{CONCLUSION}

As part of the post processing output of EFDC, it has the capability to give the value of velocity and direction of flow of water from the hydrodynamic model done. The EFDC model created was able to simulate the velocity of the water on the entire Laguna Lake in which all the results agrees with all the actual field survey done by the researcher. This hydrodynamic model can now be further developed and may be used for future studies concerning the Laguna Lake and make use of the other modules available in EFDC.

\section{ACKNOWLEDGMENT}

The researcher would like to acknowledge Mapua Institute of Technology and Department of Science and Technology, Engineering Research and Development for Technology

\section{REFERENCES}

[1] Bongco, I. G., \& Dalisay, J. S. (2012). Annual Water Quality Report of the Laguna de Bay and its Tributary Rivers. Department of Environmental and Natural Resources - Laguna Lake Development Authority.

[2] Hamrick, J. (2002). Theoretical and Computational Aspects of Sediment and Contaminant Transport in the EFDC Model. Third Draft, Tetra Tech, Inc., Fairfax, VA

[3] Hamrick, J. M. (1992a). A Three-Dimensional Environmental Dynamics Computer Code: Theoretical and Computational Aspects. Retrieved from Virginia:

[4] Hamrick, J. M. (1992b). Estuarine Environmental Impact Assessment Using a Three-Dimensional Circulation and Transport Model. Retrieved from New York:

[5] Hamrick, J. M., \& Mills, W. B. (2000). Analysis of water temperatures in Conowingo Pond as influenced by the Peach Bottom atomic power plant thermal discharge. Environmental Science \& Policy, 3, Supplement 1(0), 197-209. doi:http://dx.doi.org/10.1016/S1462-9011(00)00053-8

[6] Ji, Z.-G. (2008). Hydrodynamics and water quality: modeling rivers, lakes, and estuaries: John Wiley \& Sons.

[7] LLDA. (2008). Water Quality Report of the Seven Crater Lakes. Retrieved from Philippines: LLDA. (2014). Laguna Lake, Lake Uses.

[8] Meghna Babbar-Sebens, L. L., Kaishan Song, Shuangshuang Xie. (2013). On the Use of Landsat-5 TM Satellite for Assimilating Water Temperature Observations in 3D Hydrodynamic Model of Small Inland Reservoir in Midwestern US. Scientific Research, 2, 214-227.
[9] Mitsumoto, I., \& Santiago, A. E. (2001). A Modelling of Eutrophicatioin in Laguna de Bay as a Tool for Rational Resource Management. (2001), pp 49-73.

[10] Oceanics, G. (1980). General Oceanics Digital Flowmeter Mechanical \& Electronic Operators Manual.

[11] Philippine Sub-Global Team, UP., Los Baños. (2005). Ecosystems and People: The Philippine Millennium Ecosystem and Assessment (MA) Sub-Global Assessment. (ISBN 971-547-237-0).

[12] Tamura, H., Nadaoka, K., Paringit, E., Siringan, F., III, G. T., Villanoy, C., Yagi, H. (2003). Field Survey on Hydrodynamics and Water Quality in Manila Bay and Laguna Lake.

[13] Wang, Y., Jiang, Y., Liao, W., Gao, P., Huang, X., Wang, H., . Lei, X. 3-D Hydro-Environmental Simulation of Miyun Reservoir, Beijin. Journal of Hydro-environment doi:http://dx.doi.org/10.1016/j.jher.2013.09.002

[14] Wu, G., \& Xu, Z. (2011). Prediction of algal blooming using EFDC model: Case study in the Daoxiang Lake. Ecological Modelling, 222(6), 1245-1252. doi:http://dx.doi.org/10.1016/j.ecolmodel.2010.12.021

[15] Zhao, L., Li, Y., Zou, R., He, B., Zhu, X., Liu, Y., . . Zhu, Y. (2013). A three-dimensional water quality modeling approach for exploring the eutrophication responses to load reduction scenarios in Lake Yilong (China). Environmental Pollution, 177(0),13-21. doi:http://dx.doi.org/10.1016/j.envpol.2013.01.047

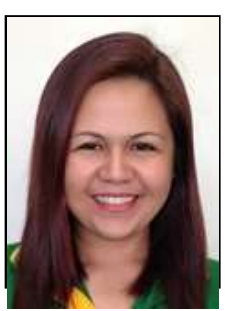

Armi Mendoza Cunanan, born on the $23^{\text {rd }}$ of June 1982, youngest among the five siblings of Gregorio and Adora. She graduated Bachelor of Science in Civil Engineering from Technological Institute of the Philippines in 2005 and Master of Science in Environmental Engineering from Mapua Institute of Technology in 2010. As a licensed Civil Engineer, she was able to work in various fields such as construction, construction management, and academe, then decided to pursue Doctor of Philosophy in Environmental Engineering in Mapua Institute of Technology. Aside from her good academic background, she also has passion for nature. As a mountain climber she was able to conquer all the highest peak of Luzon, Visayas, and Mindanao in the Philippines and the Haba Snow Mountain in Yunnan, China. She is now blessed with a loving husband and a son named Raim Vedder. 